International Journal of Research Studies in Electrical and Electronics Engineering(IJRSEEE)

Volume 5, Issue 1, 2019, PP 24-37

ISSN 2454-9436 (Online)

DOI: http://dx.doi.org/10.20431/2454-9436.0501004

www.arcjournals.org

\title{
HVDC over HVAC Transmission System: Fault Conditions Stability Study
}

\author{
Ali M. Eltamaly ${ }^{1^{*}}$, Yehia Sayed ${ }^{2}$, Abou-Hashema M. El-Sayed ${ }^{2}$ and Amer Nasr A. Elghaffar ${ }^{2}$ \\ ${ }^{* 1}$ Electrical Engineering Department, Mansoura University, Mansoura, Egypt \\ ${ }^{2}$ Electrical Engineering Department, Minia University, Minia, Egypt
}

*Corresponding Author: Ali M. Eltamaly, Electrical Engineering Department, Mansoura University, Mansoura, Egypt.

\begin{abstract}
Electric Faults can be defined as the flow of a massive current through an alternative path which leads to cause serious equipment's damage, interruption of power, personal injury or death. High Voltage Alternating Current (HVAC) is the most effective and efficient way for energy transmission in modern power systems around the world. But, it's important to use High Voltage Direct Current (HVDC) system to link between different frequency networks and at transmitting energy on very long distance. HVDC operates at one side "converter station", where, the AC is converted to DC, which is then transmitted from sending end converter station, converted back to AC at receiving end to feed the other electrical network. This paper discusses the performance of the electrical grid system at the fault occurrence in HVAC and HVDC system. Also, this paper introduces the mathematical calculation steps at different faults conditions in the transmission line. The simulation of the fault current in this paper has been performed by using MATLAB/Simulink to compare the output fault current in HVAC and HVDC system.
\end{abstract}

Keywords: Power System, HVAC, HVDC, MATLAB; Stability, Faults.

\section{INTRODUCTION}

With the increasing on the demand power, the electrical grid extended and classified to generation, transmission and distribution [1]. This increasing is required to improve the system by the new sources as the renewable energy. The renewable energy sources are considered more economic and high clean energy for the environment [2]. To link the renewable sources with the power system, its important to save the system with stable operation [3]. The increasing loads and the power system extension system can affect on the voltage stability and the unstable reactive power [4]. The Flexible AC Transmission System Devices voltage (FACT) is considered the optimum techniques to save control the system voltage and to save the feeding loads [5].

Stability in the power system is defined as the accurate operation of the system by recovering a state of operating balance after any abnormal condition such as faults, over or under voltage cases at switching time, load rejection and at loss of excitation [6]. Over Head Transmission Line (OHTL) is the one from main parts in the power system that transmits the power from the generation to the electrical loads [7]. OHTL is the most part that's face the faults in the system. But, it's impossible to direct link between different frequency networks such as $50 \mathrm{~Hz}$ and $60 \mathrm{~Hz}$ directly, so HVDC can solve this problem, for example, the link between Egypt and Saudi Arabia is considered as a research problem in this paper. This multi-terminal HVDC project works at a DC voltage of $500 \mathrm{kV}$ and a power rating of $3000 \mathrm{MW}$ is investigated in this research [8]. This project involves $1500 \mathrm{~km}$ of DC OHTL and $16 \mathrm{~km}$ of DC marine cable. This system can be operated to transmit or receive power between two networks using AC/DC/AC converters. HVDC is characterized by low power losses compared to HVAC system. Also, HVDC can transmit power for very long distance economically than HVAC system as illustrated in Figure1. HVDC has been extensively deployed in submarine applications compared to HVAC system. The HVDC has the unusual ability to connect asynchronous networks; this capability will extend in the future with greater numbers of micro-grids and more using of renewable energy systems in modern power systems [9]. Furthermore, HVDC technologies can provide stability with controlling of power flow, and the ability to segment parts of the power system all of which can enhance the grid's flexibility, International Journal of Research Studies in Electrical and Electronics Engineering (IJRSEEE) Page | 24 
reliability, and resilience [10]. This paper discusses the HVAC transmission system and HVDC operation system at stable condition, also shows the fault current result at faults due to HVAC and HHDC system to be used with transmission system.

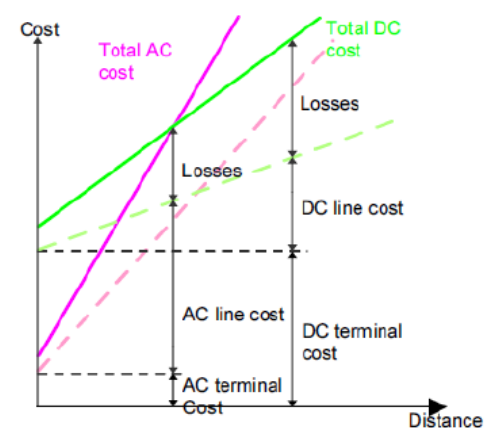

Figure1. Characteristic Curves for the Relations between Cost with Distance for HVDC and HVAC.

\section{STABILITY IN HVAC AND HVDC SYSTEMS}

The faults in OHTL are involves the arcing phenomena triggered by the dust, humidity and the weather factor. The underground cable faults are less frequent, but its more permanent, that's occurring due to the electrical or environmental stresses and insulation damage [8-12]. The protection system should be providing fast for operation, localizing fault, reliability, selectivity and take appropriate action to isolate the fault zone.

\subsection{HVAC Transient Stability System}

Figure2 shows the single line diagram for simple system contain two sources supply. Figure3 shows the power angle curve for the power system operation, where, atstable operations for the power system the system operates at $\delta_{0}$, the output of electric power produces by electric torque that equalized with the mechanical torque which applied to the rotor shaft for the generator[13].At any fault in the system, its will leads to increasing in the load current, so at this moment the mechanical power for the generator not equalized with the electrical power for the electrical loads, this case known an unstable condition in the system that's will increase the power angle to 90 degrees. At this point, the load current could only be met by increasing voltage source $E_{s}, E_{R}$. Left source has a phase angle advance equal to $\theta$, and this angle will vary during the fault[9-14]. The power transferred from one source to another reach to maximum value $\mathrm{P}_{\mathrm{MAX}}$ when angle $\delta$ is 90 degrees, by increase the angle $\delta$, this will cause a decrease of power transfer.

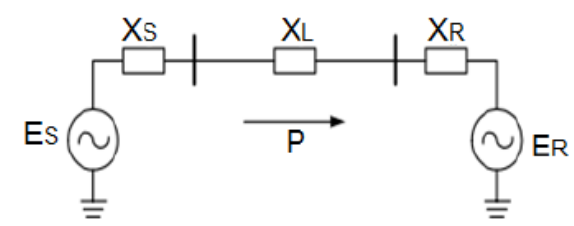

Figure2. Simple Power System for Two Sources Supply

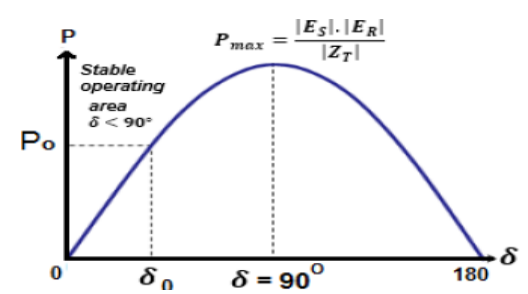

Figure3. Stable Power System Transient

\subsection{HVDC Stability System}

Basic rules in HVDC system at transmitting end is to convert HVAC to HVDC and at receiving end convert this HVDC will be converted back to HVAC. These changes can be applied by rectifiers and inverters, as shown in Figure4 and Figure5, respectively. The converter works in both ends should allow the power to flow in both directions by controlling the firing angle in both converters. Moreover, the important devices assist with this system are filters, thyristors, (IGBT) and Voltage Source Converter (VSC) [15]. The differential firing of the thyristors in two series-connected gates is International Journal of Research Studies in Electrical and Electronics Engineering (IJRSEEE) Page | 25 
used to produce a decrease in both the harmonic generation and the reactive volt-ampere absorption for the rectifier mode of operation [16]. Different strategies can be used to reduce harmonics in the line currents [17-18]. There are various methods for controlling the HVDC in the multi-terminal grid but the protecting system is the main supporting. HVDC system still lagging HVAC systems, without rated protection devices and logic. But, by using double thyristors switches, the diode freewheeling effect can be eliminated and the fault in dc line can be calculated [11-14]. This clears the fault without commanding trip to open the Circuit Breaker (CB), and can operate fast with automatic power transmission recovery, which considerably improve the dependability of the HVDC system. Fault action in the multi-terminal HVDC can be detected by supervising to any changes in some system parameters. The accurate methods to detect the fault by using three parameters, as suggested in, initial current change, rise time of the first wave front of the branch current and the oscillation pattern. Because of the time to clear fault is the critical command, so, using the local information at each VSC in their protection scheme is faster than using telecommunication system.

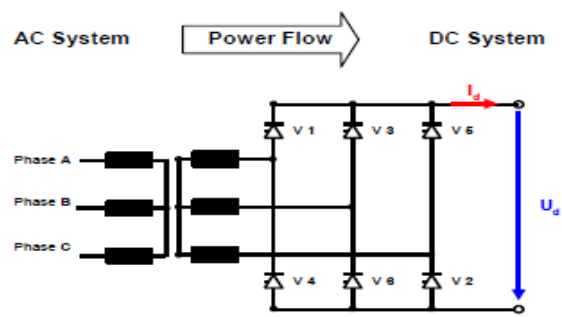

Figure4. Operating the Rectifier with HVDC System

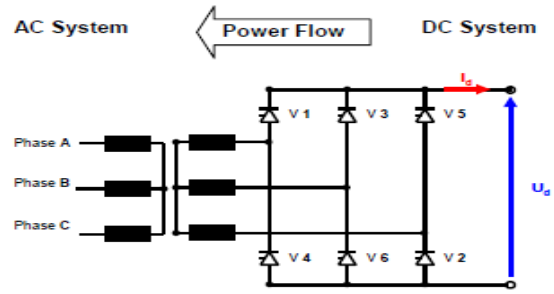

Figure5. Operating the Rectifier with HVAC System

\section{Classifications For FAults In POWER System}

Faults conditions in the power system can be classified related to the types of fault. Where, at the fault is three phases with the ground its known as the symmetrical fault, otherwise its known as unsymmetrical fault. The main reason of the fault is the insulation fails or one from lines touch with the ground [19-20]. To analyze the fault, it's important to simulate the fault in three components that's positive sequence and negative sequence and zero sequence. Figure6a shows the positive sequence components are equal in magnitude values and the angle difference between each phase by 120 degrees with the same sequence as the original phases, also the currents and voltages follow the same cycle in typical counter clockwise rotation electrical system that's called the "abc". Figure6b shows the negative sequence components that's equalized in magnitude, the phase shift between phases is $120^{\circ}$ and its opposite phase sequence from the original system that's identified as "acb". Figure6c shows the zero sequence components that's three-phase equalized in magnitude and the phase shift between phases is zero. The zero sequence components are not presented at symmetrical fault.

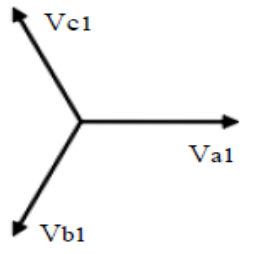

A. Positive

Sequence Component

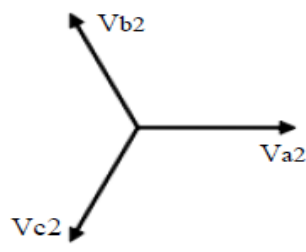

b. Neqative Sequence Component

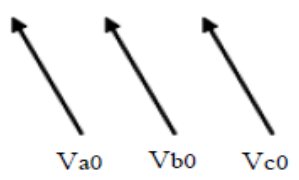

c. Zero

Sequence

Component

Figure6. Analyze the Sequence Component in the Power System 
Firstly, the Change in magnitude:

$\mathrm{a}=1 \angle 120^{\circ}=-0.5+\mathrm{j} 0.866$

$\mathrm{a}^{2}=1 \angle 240^{\circ}=-0.5-\mathrm{j} 0.866$

$\mathrm{a}^{3}=1 \angle 360^{\circ}=1+\mathrm{j} 0$

From these equations, useful combinations can be derived

$1+\mathrm{a}+\mathrm{a}^{2}=0$

$1-\mathrm{a}^{2}=\sqrt{3} \angle 30^{\circ}$

Or

$1-\mathrm{a}=\sqrt{3} \angle-30^{\circ}$

$\mathrm{a}^{2}-\mathrm{a}=\sqrt{3} \angle 270^{\circ}$

Or

$\mathrm{a}-\mathrm{a}^{2}=\sqrt{3} \angle 90^{\circ}$

Any three-phase system of phasors will always be the sum of the three components.

Positive sequence voltage is:

$\mathrm{V}_{\mathrm{a} 1} \mathrm{~V}_{\mathrm{b} 1} \mathrm{~V}_{\mathrm{c} 1}$

Negative sequence voltage is:

Zero sequence voltage is:

$$
\mathrm{V}_{\mathrm{a} 2} \mathrm{~V}_{\mathrm{b} 2} \mathrm{~V}_{\mathrm{c} 2}
$$

$$
\mathrm{V}_{\mathrm{a} 0} \mathrm{~V}_{\mathrm{b} 0} \mathrm{~V}_{\mathrm{c} 0}
$$

The original system phase components can be presented from $\mathrm{Va}, \mathrm{Vb}$ and $\mathrm{Vc}$

$\left[\begin{array}{c}\mathrm{V}_{\mathrm{a}}=\mathrm{V}_{\mathrm{a} 0}+\mathrm{V}_{\mathrm{a} 1}+\mathrm{V}_{\mathrm{a} 2} \\ \mathrm{~V}_{\mathrm{b}}=\mathrm{V}_{\mathrm{b} 0}+\mathrm{V}_{\mathrm{b} 1}+\mathrm{V}_{\mathrm{b} 2} \\ \mathrm{~V}_{\mathrm{c}}=\mathrm{V}_{\mathrm{c} 0}+\mathrm{V}_{\mathrm{c} 1}+\mathrm{V}_{\mathrm{c} 2}\end{array}\right]$

From equations (1) to (5) Zero sequence component

Positive sequence component

$$
\mathrm{V}_{\mathrm{a} 0}=\mathrm{V}_{\mathrm{b} 0}=\mathrm{V}_{\mathrm{c} 0}
$$

$\mathrm{V}_{\mathrm{b} 1}=\mathrm{a}^{2} \mathrm{~V}_{\mathrm{a} 1}$

$\mathrm{V}_{\mathrm{c} 1}=\mathrm{a} \mathrm{V}_{\mathrm{a} 1}$

Negative sequence component

$\mathrm{V}_{\mathrm{b} 2}=\mathrm{a} \mathrm{V}_{\mathrm{a} 2}$

$\mathrm{V}_{\mathrm{c} 2}=\mathrm{a}^{2} \mathrm{~V}_{\mathrm{a} 2}$

$\mathrm{Va}, \mathrm{Vb}$ and $\mathrm{Vc}$ can be expressed in terms of phase "a" components only as:

$$
\begin{gathered}
V_{\mathrm{a}}=\mathrm{V}_{\mathrm{a} 0}+\mathrm{V}_{\mathrm{a} 1}+\mathrm{V}_{\mathrm{a} 2} \\
\mathrm{~V}_{\mathrm{b}}=\mathrm{V}_{\mathrm{a} 0}+\mathrm{a}^{2} \mathrm{~V}_{\mathrm{a} 1}+\mathrm{a} \mathrm{V}_{\mathrm{a} 2} \\
\mathrm{~V}_{\mathrm{c}}=\mathrm{V}_{\mathrm{a} 0}+\mathrm{a} \mathrm{V}_{\mathrm{a} 1}+\mathrm{a}^{2} \mathrm{~V}_{\mathrm{a} 2}
\end{gathered}
$$

This equation can be accomplished in a matrix form:

$\left[\begin{array}{c}V_{\mathrm{a}} \\ \mathrm{V}_{\mathrm{b}} \\ \mathrm{V}_{\mathrm{c}}\end{array}\right]=\left[\begin{array}{ccc}1 & 1 & 1 \\ 1 & \mathrm{a}^{2} & \mathrm{a} \\ 1 & \mathrm{a} & \mathrm{a}^{2}\end{array}\right]\left[\begin{array}{c}\mathrm{V}_{\mathrm{a} 0} \\ \mathrm{~V}_{\mathrm{a} 1} \\ \mathrm{~V}_{\mathrm{a} 2}\end{array}\right]$

Equation (8) can be written as:

$$
\begin{gathered}
A=\left[\begin{array}{ccc}
1 & 1 & 1 \\
1 & a^{2} & a \\
1 & a & a^{2}
\end{array}\right] \\
{\left[\begin{array}{c}
V_{a} \\
V_{b} \\
V_{c}
\end{array}\right]=A\left[\begin{array}{c}
V_{a 0} \\
V_{a 1} \\
V_{a 2}
\end{array}\right]}
\end{gathered}
$$

This equation can be reversed in order to obtain the positive, negative and zero sequences from the system phasors

International Journal of Research Studies in Electrical and Electronics Engineering (IJRSEEE) Page | 27 
$\left[\begin{array}{c}\mathrm{V}_{\mathrm{a} 0} \\ \mathrm{~V}_{\mathrm{a} 1} \\ \mathrm{~V}_{\mathrm{a} 2}\end{array}\right]=\mathrm{A}^{-1}\left[\begin{array}{c}\mathrm{V}_{\mathrm{a}} \\ \mathrm{V}_{\mathrm{b}} \\ \mathrm{V}_{\mathrm{c}}\end{array}\right]$

Where,

$$
\mathrm{A}^{-1}=\frac{1}{3}\left[\begin{array}{ccc}
1 & 1 & 1 \\
1 & \mathrm{a} & \mathrm{a}^{2} \\
1 & \mathrm{a}^{2} & \mathrm{a}
\end{array}\right]
$$

\subsection{Symmetrical Fault Analysis}

Three-phase fault is known the symmetrical fault where the voltage is zero in the fault site. Figure 7 shows the general simulation for the symmetrical fault, Figure8 shows the sequence diagram of a symmetrical fault [20-21].

The corresponding currents for each of the sequences is:

$I_{a 0}=0$

$I_{a 2}=0$

$I_{a 1}=\frac{1 \angle 0}{Z_{1}+Z_{f}}$

At fault impedance $\mathrm{Zf}$ is zero,

$$
I_{a 1}=\frac{1 \angle 0}{Z_{1}}
$$

Substituted into equation (13)

$\left[\begin{array}{l}I_{a f} \\ I_{b f} \\ I_{c f}\end{array}\right]=\left[\begin{array}{ccc}1 & 1 & 1 \\ 1 & a^{2} & a \\ 1 & a & a^{2}\end{array}\right]\left[\begin{array}{c}0 \\ I_{a 1} \\ 0\end{array}\right]$

So, by solving the equations:

$$
\begin{gathered}
I_{a f}=\frac{1 \angle 0}{Z_{1}} \\
I_{b f}=\frac{1 \angle 240}{Z_{1}} \\
I_{c f}=\frac{1 \angle 120}{Z_{1}}
\end{gathered}
$$

And the phase Voltage is:

$V_{a f}=V_{b f}=V_{c f}=0$

$V_{a 0}=V_{a 1}=V_{a 2}=0$

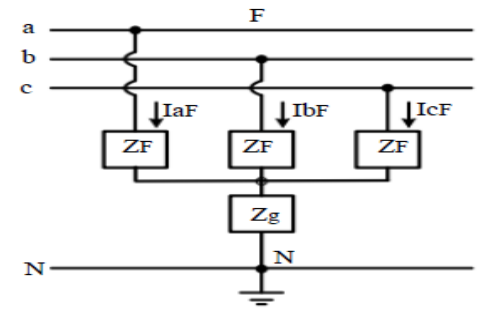

Figure7. General Simulation of a Three-Phase Fault

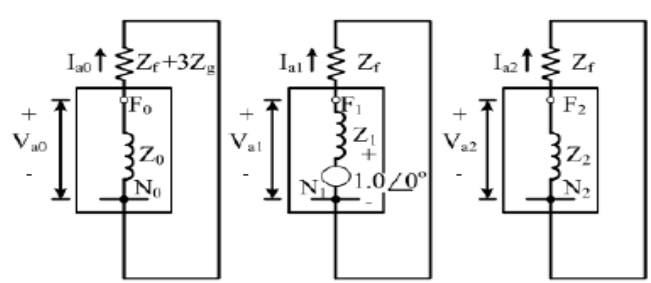

Figure8. Sequence Diagram of a Symmetrical Fault 


\subsection{Single Line to Ground Fault}

At single line to ground fault there is one conductor falls to ground as shown in Figure9, where $\mathrm{F}$ is the fault point with impedances Zf. Figure10 shows the sequences network single line to ground fault diagram [20-22].

The zero, positive, and negative-sequence currents are equals as shown in Figure10. So:

$I_{a 0}=I_{a 1}=I_{a 2}=\frac{1 \angle 0}{Z_{0}+Z_{1}+Z_{2}+3 Z_{f}}$

$$
\left[\begin{array}{l}
I_{a f} \\
I_{b f} \\
I_{c f}
\end{array}\right]=\left[\begin{array}{ccc}
1 & 1 & 1 \\
1 & a^{2} & a \\
1 & a & a^{2}
\end{array}\right]\left[\begin{array}{l}
I_{a 0} \\
I_{a 1} \\
I_{a 2}
\end{array}\right]
$$

And by solving the fault current equation for phase a

$I_{a f}=I_{a 0}+I_{a 1}+I_{a 2}$

That's also, can be written as:

$I_{a f}=3 I_{a 0}=3 I_{a 1}=3 I_{a 2}$

$V_{a f}=I_{a f} Z_{a f}$

The voltage at faulted phase a can be obtained by substituting

$$
V_{a f}=3 Z_{f} I_{a 1}
$$

But,

$$
V_{a f}=V_{a 0}+V_{a 1}+V_{a 2}
$$

So,

$V_{a 0}+V_{a 1}+V_{a 2}=3 Z_{f} I_{a 1}$

With the results obtained for sequence currents, the sequence voltages can be obtained from

$\left[\begin{array}{l}V_{a 0} \\ V_{b 1} \\ V_{c 2}\end{array}\right]=\left[\begin{array}{c}0 \\ 1 \angle 0 \\ 0\end{array}\right]-\left[\begin{array}{ccc}1 & 1 & 1 \\ 1 & a^{2} & a \\ 1 & a & a^{2}\end{array}\right]\left[\begin{array}{c}I_{a 0} \\ I_{a 1} \\ I_{a 2}\end{array}\right]$

By solving equation (21);

$V_{a 0}=-Z_{0} I_{a 0}$

$V_{b 1}=1-Z_{1} I_{a 1}$

$V_{c 2}=-Z_{2} I_{a 2}$

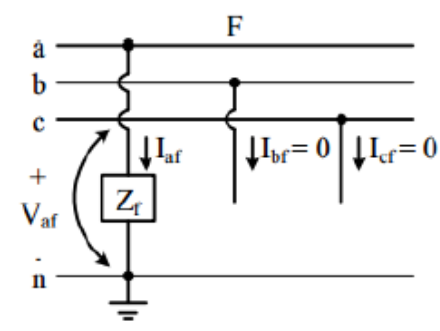

Figure9. General Simulation of a Single Line-To-Ground Fault

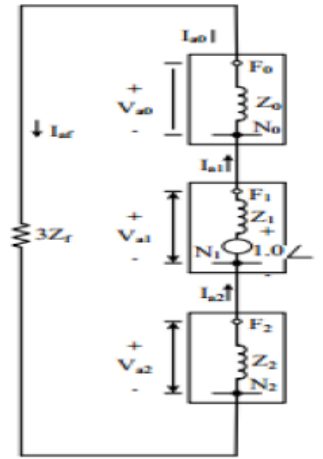

Figure10. Sequence diagram of a single line-to-ground fault 


\subsection{Line-to-Line Fault}

Figure 11 shows two lines are shorted that consider unsymmetrical fault, where, $\mathrm{F}$ is the fault point with impedances Zf. Figure 12 shows the sequences network Line to line fault diagram [20]. The characteristic of line to line fault impedance magnitude could vary over a wide range making very hard to predict its upper and lower limits and at the impedance is zero so, it's very high fault current.

From the figures

$I_{a f}=0, I_{b f}=-I_{c f}$

$V_{b c}=Z I_{b f}$

And the sequence currents can be obtained as:

$I_{a 0}=0$

$I_{a 1}=-I_{a 2}=\frac{1 \angle 0}{Z_{1}+Z_{2}+Z_{f}}$

At $\mathrm{Zf}$ is zero

$I_{a 1}=-I_{a 2}=\frac{1 \angle 0}{Z_{1}+Z_{2}}$

The fault currents for phase $\mathrm{b}$ and $\mathrm{c}$ can be obtained that:

$$
\begin{gathered}
\mathrm{I}_{\mathrm{bf}}=-\mathrm{I}_{\mathrm{cf}}=\sqrt{3} \mathrm{I}_{\mathrm{a} 1}<-90 \\
V_{a 0}=0 \\
V_{a 1}=1-Z_{1} I_{a 1} \\
V_{a 2}=-Z_{2} I_{a 2}=Z_{2} I_{a 1}
\end{gathered}
$$

So,

$V_{a f}=V_{a 1}+V_{a 2}=1+I_{a 1}\left(Z_{2}-Z_{1}\right)$

$V_{b f}=a^{2} V_{a 1}+a V_{a 2}=a^{2}+I_{a 1}\left(a Z_{2}-a^{2} Z_{1}\right)$

$V_{c f}=a V_{a 1}+a^{2} V_{a 2}=a+I_{a 1}\left(a^{2} Z_{2}-a Z_{1}\right)$

Finally, at line-to-line fault the line-to-line voltages equations:

$V_{a b}=V_{a f}-V_{b f}$

$V_{b c}=V_{b f}-V_{c f}$

$V_{c a}=V_{c f}-V_{a f}$

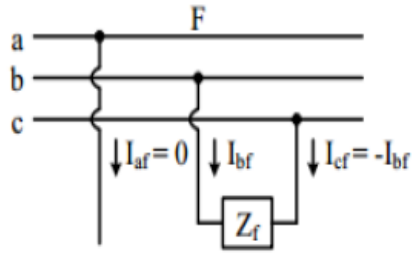

Figure11. General Simulation for Line To Line Fault

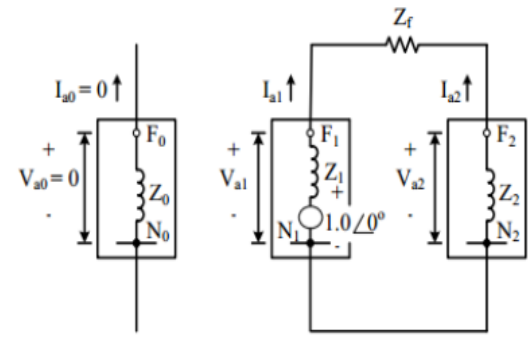

Figure12. Sequence Diagram of a Line-To-Line Fault

\subsection{Double Line-to-Ground Fault}

A double line-to-ground fault represents an unsymmetrical fault. Figure13 shows the double line to ground fault, where $\mathrm{F}$ is the fault point with impedances $\mathrm{Zf}$ and the impedance from line to ground 
Zg. Figure 14 shows the sequences network line to line to ground fault diagram [20-22].

The major problem when analyzing this type of fault is the assumption of the fault impedance $\mathrm{Zf}$, and the value of the impedance towards the ground $\mathrm{Zg}$.

From Figure14, the analysis equations can be observed that:

$I_{a f}=0$

$V_{b f}=\left(Z_{f}+Z_{g}\right) I_{b f}+Z_{g} I_{c f}$

$V_{c f}=\left(Z_{f}+Z_{g}\right) I_{c f}+Z_{g} I_{b f}$

And the sequence currents can be obtained as:

$$
I_{a 0}=0
$$

$I_{a 1}=\frac{1 \angle 0}{\left(Z_{1}+Z_{f}\right)+\frac{\left(z_{2}+Z_{f}\right)\left(z_{0}+Z_{f}+3 Z_{g}\right)}{\left(z_{2}+Z_{f}\right)+\left(z_{0}+Z_{f}+3 Z_{g}\right)}}$

$I_{a 2}=-\left[\frac{\left(Z_{0}+Z_{f}+3 Z_{g}\right)}{\left(Z_{2}+Z_{f}\right)+\left(Z_{0}+Z_{f}+3 Z_{g}\right)}\right] I_{a 1}$

$I_{a 0}=-\left[\frac{\left(Z_{2}+Z_{f}\right)}{\left(Z_{2}+Z_{f}\right)+\left(Z_{0}+Z_{f}+3 Z_{g}\right)}\right] I_{a 1}$

An alternative method is,

$I_{a f}=0=I_{a 0}+I_{a 1}+I_{a 2}$

$I_{a 0}=-\left(I_{a 1}+I_{a 2}\right)$

If $\mathrm{Zf}$ and $\mathrm{Zg}$ are both equal to zero, then the positive-, negative-, and zero sequences can be obtained from:

$I_{a 1}=\frac{1 \angle 0}{\left(Z_{1}+Z_{f}\right)+\frac{\left(Z_{2}\right)\left(Z_{0}\right)}{\left(Z_{2}\right)+\left(Z_{0}\right)}}$

$I_{a 2}=-\left[\frac{\left(Z_{0}\right)}{\left(Z_{2}\right)+\left(Z_{0}\right)}\right] I_{a 1}$

$I_{a 0}=-\left[\frac{\left(Z_{2}\right)}{\left(Z_{2}\right)+\left(Z_{0}\right)}\right] I_{a 1}$

By solve the equations so, phase $\mathrm{b}$ and $\mathrm{c}$ fault currents is:

$I_{b f}=I_{a 0}+a^{2} I_{a 1}+a I_{a 2}$

$I_{c f}=I_{a 0}+a I_{a 1}+a^{2} I_{a 2}$

The total fault current flowing into the neutral is:

$I_{n}=3 I_{a 0}=I_{b f}+I_{c f}$

So, the sequences voltages can be obtained as:

$V_{a 0}=-Z_{0} I_{0}$

$V_{a 1}=1-Z_{1} I_{a 1}$

$V_{a 2}=-Z_{2} I_{a 2}=Z_{2} I_{a 1}$

So, the phase voltage is:

$V_{a f}=V_{a 0}+V_{a 1}+V_{a 2}$

$V_{b f}=V_{a 0}+a^{2} V_{a 1}+a V_{a 2}$

$V_{c f}=V_{a 0}+a V_{a 1}+a^{2} V_{a 2}$

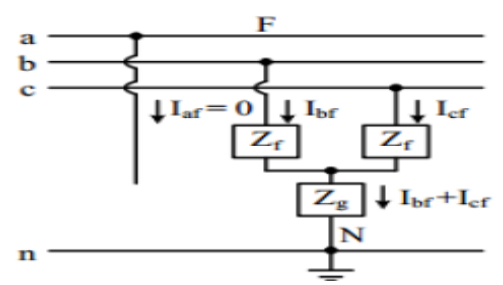

Figure13. General Simulation of a Double Line-To-Ground Fault

International Journal of Research Studies in Electrical and Electronics Engineering (IJRSEEE) Page | 31 


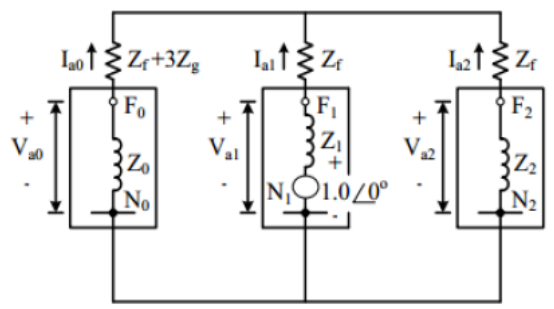

Figure14. Sequence Diagram of a Double Line-To-Ground Fault

\section{Fault Analysis Simulation In HVdC And HVaC}

HVDC system and HVAC system are symmetrical for the reason of the expecting of the faults in the power system [23]. Furthermore, some failure in HVDC system can be created in the inverter and converter (AC-DC, DC-AC) stations [24]. OHTL is generally more expecting faults, such as lightning strikes than buried transmission systems [25]. Faults on cables are consider a permanent for damage, that's happen in the insulation and it isn't self-healing air like on OHTLs [15-17]. Also, the faults in the cables requires large cavity to identify the location of the fault to maintain and return the system to service [26]. This is dangerous for submarine HVDC cable systems, where replacement or maintain means raising the cable from the seabed, removing the failed part and replacing it with a new section. A fault on a submarine cable is therefore very serious and can result in the HVDC system being out of service for up to six months. To simulate and compare between faults in HVDC and HVAC, by simulating the HVAC system in Figure15 and HVDC 12-Pulse thyristor converters system in Figure16. This system is uses to link between $50 \mathrm{~Hz}$ system and $60 \mathrm{HZ}$ system by transmission voltage $500 \mathrm{kV}, 0.8$ lagging to transmit 2000 MVA. These systems have been simulated by using MATLAB/SIMULINK software with applying the fault near to receiving end bus and different positions, with considering the multi sources for this system. The following points show different cases of faults that might be happened in the terminals of HVDC systems:

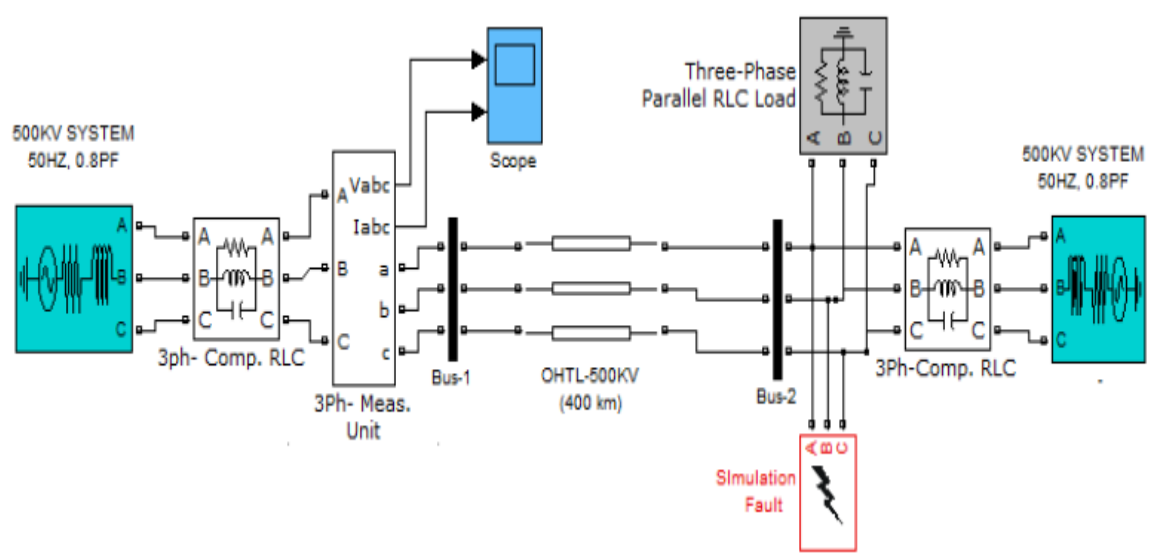

Figure15. HVAC Power Transmission System

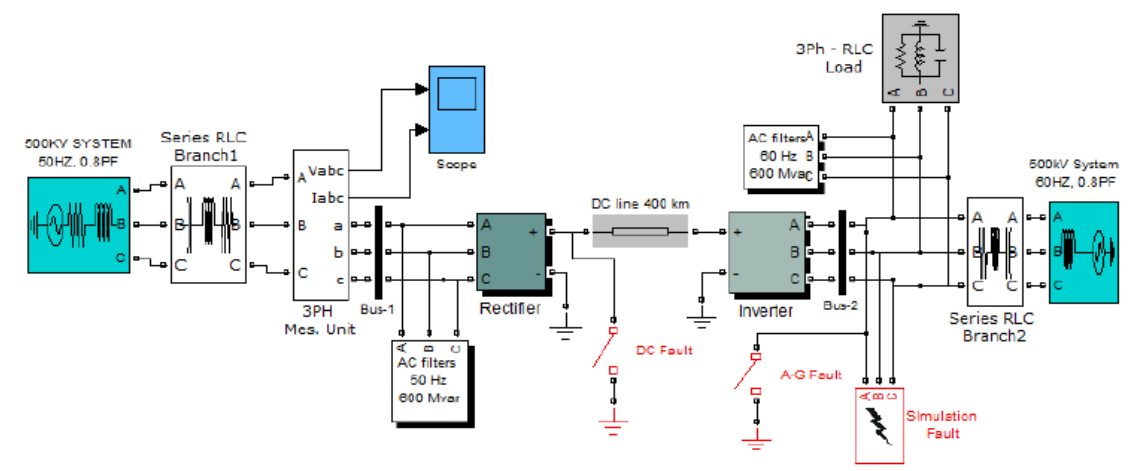

Figure16. HVDC Power Transmission System 


\subsection{Single Line to Ground Fault Analysis [Case:1]}

The simulation results of both faults between HVAC and HVDC system at Single Line to Ground (SLG) fault [23-26] are shown in Figure17and Figure 18, where, SLG fault has about 85\% from the OHTL faults. This comparison uses the same line parameters for HVAC and HVDC and line length. Figure17 shows the result for SLG fault current values for HVAC system. Figure18 shows the SLG fault current for HVDC. Comparing between these two faults will prove that, the effect of SLG fault current is less in HVDC system compared to HVAC system. From results shown in Table (1), the fault current is higher with HVAC system compared to HVDC system.

\subsection{Line to Line Fault Analysis [Case:2]}

Line to line fault consider 10\% from faults occurs in the system. Figure19 and Figure20 shows the fault current wave value for HVAC and HVDC systems, respectively. Table (1) shows the results of line to line fault results. It is clear from this results that, the fault current in HVAC system is very high compared to HVDC system.

\subsection{Three Phases to Ground Fault Analysis [Case:3]}

The simulation results for the fault current at symmetrical fault in HVAC and HVDC are shown in Figure21 and Figure22, respectively. Table (1) shows the same results as values. From the results, the fault current in HVAC is very high compared to HVDC system

Also, by comparing the fault for three phases to ground fault in HVAC system with the fault in the HVDC cable, will found the value of three phase to ground fault in HVAC is higher than HVDC fault cable as shown in Figure23.

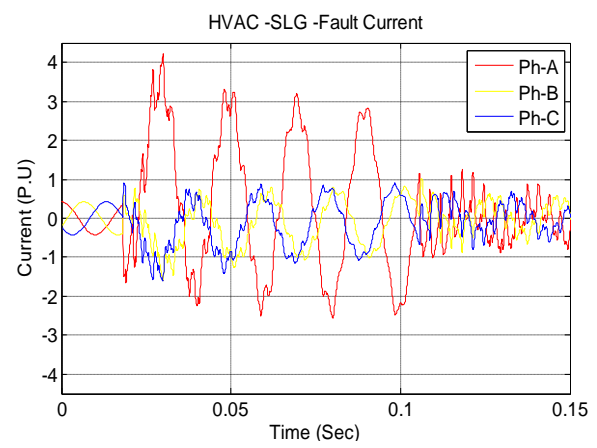

Figure17. SLG Fault Current for HVAC System

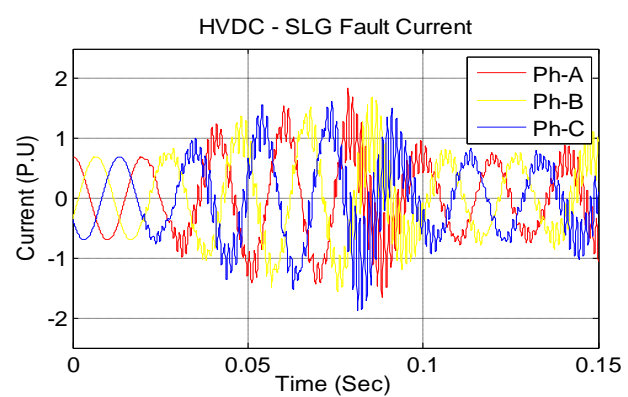

Figure18. SLG Fault Current for HVDC System

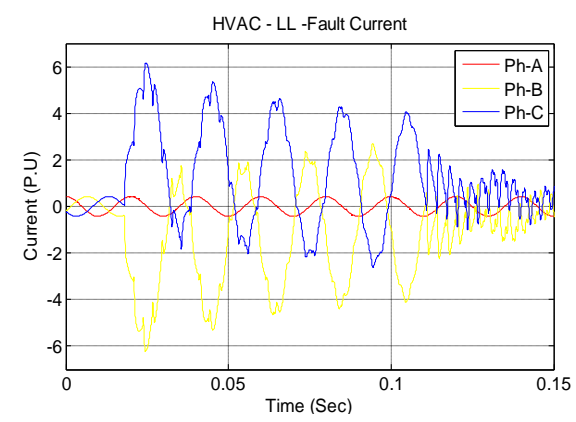

Figure19. Line to Line Fault Current for HVAC System

International Journal of Research Studies in Electrical and Electronics Engineering (IJRSEEE) Page | 33 


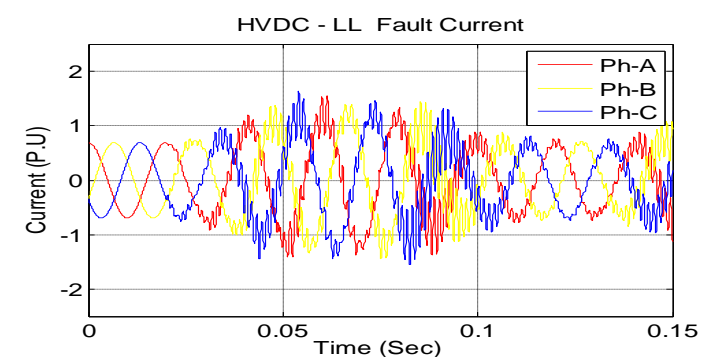

Figure20. Line to Line Fault Current for HVDC System

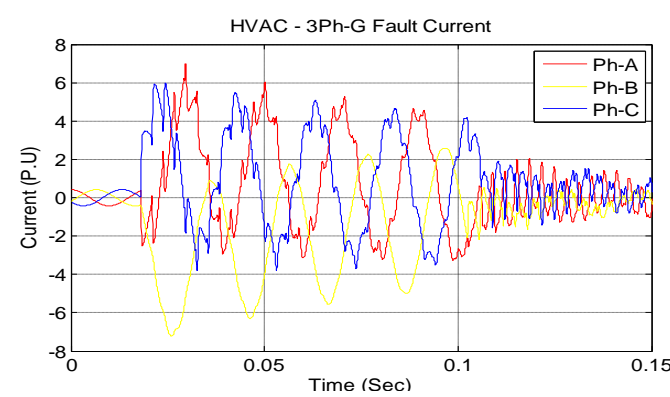

Figure21. Three Phase to Ground Fault for HVAC System

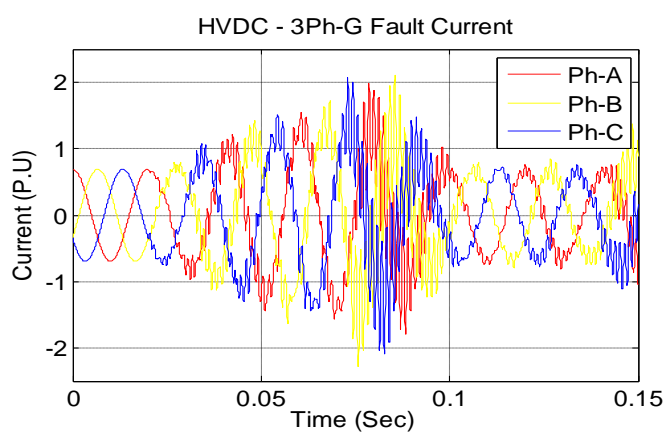

Figure22. Three Phase to Ground Fault for HVDC System

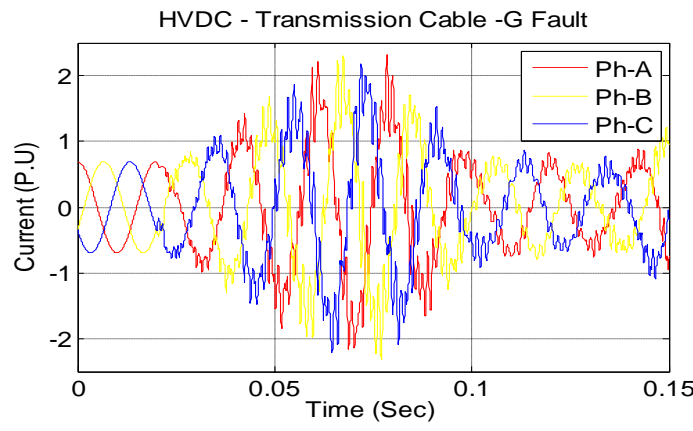

Figure23. HVDC Cable to Ground Fault

Table1. HVAC System Comparing With HVDC System

\begin{tabular}{|c|c|c|c|}
\hline Fault & Point analyze & HVAC current (P.U) & HVDC current(P.U) \\
\hline \multirow{2}{*}{ Single line to ground fault } & Peak up & 4.2 & 1.7 \\
\cline { 2 - 4 } & Peak down & 2.6 & 1.6 \\
\hline \multirow{2}{*}{ Line to line fault } & Peak up & 6.09 & 1.60 \\
\cline { 2 - 4 } & Peak down & 6.08 & 1.6 .0 \\
\hline \multirow{2}{*}{ 3phase to ground fault } & Peak up & 7.04 & 2.1 \\
\cline { 2 - 4 } & Peak down & 7.02 & 2.2 \\
\hline \multirow{2}{*}{$\begin{array}{c}\text { HVDC Transmission Cable-G } \\
\text { fault }\end{array}$} & Peak up & - & 2.07 \\
\cline { 2 - 4 } & Peak down & - & 2.2 \\
\hline
\end{tabular}

International Journal of Research Studies in Electrical and Electronics Engineering (IJRSEEE) Page | 34 


\subsection{Comparing System Status During Faults}

From the discussion in the fault analysis between HVAC and HVDC system, it is noted that, the fault current in HVAC system effects on the phase fault more than other phases, and in HVDC system noted that's, the fault current effects on all 3-phases. By, study the generation system operation, it is found that, the increasing on one phase current can affect the mechanical part because the high unbalance current. So, the fault in the HVDC is more stable in the rotating part in the generator with comparing HVAC system. Figure24 shows the disturb voltage on HVAC system at SLG fault, Figure25 shows the HVDC voltage at SLG fault.

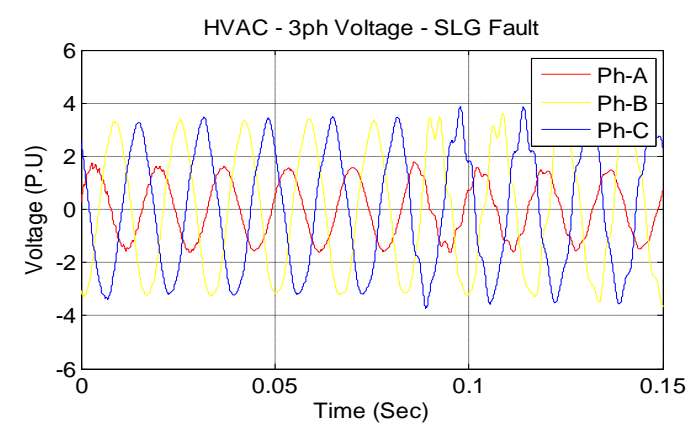

Figure24. 3Ph-Voltage at SLG Fault for HVAC System

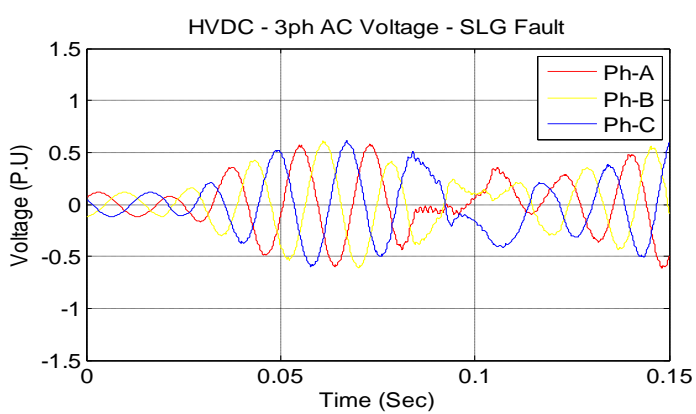

Figure25. 3Ph-Voltage at SLG Fault for HVDC System

\section{CONCLUSION}

Nowadays, HVDC is very important in transmission energy between networking having different frequencies or in case of transmitting high power over very long distance. HVDC system has a lower cost compared to HVAC, also, the power losses with HVDC is lower than HVAC because of absence the inductance. This paper shows an overview of control and operation for the HVDC system that's can be used to link between two different frequencies. HVDC can easily connect different frequencies freely without affecting on the voltage stability. Furthermore, HVDC doesn't create reactive power, so it's more stable than HVAC. Also, this paper discussed the fault current analysis between HVAC and HVDC systems. This study used $500 \mathrm{kV}, 0.8$ power factor lagging to transmit 2000 MVA power between two grids for $400 \mathrm{~km}$. The study done under SLG, LL, and three phase to ground faults. The results show that, the fault current at HVAC is higher than HVDC, where for single line to ground fault the HVAC fault is 2.625 times compared to HVDC system. At line to line fault the fault current of HVAC fault current is 3.45 times the one for HVDC. For three-phase to ground fault the fault current of HVAC system is 3.35 times the one from HVDC. Also, at the fault condition the voltage system is stable for HVDC from HVAC system.

\section{REFERENCES}

[1] Ali Eltamaly and Amer Nasr A. Elghaffar, Yehia Sayed and Abou-Hashema M. El-Sayed. (2018). Mitigation Voltage Sag Using DVR with Power Distribution Networks for Enhancing the Power System Quality. IJEEAS Journal. ISSN: 2600 -7495, Vol.1 No.2. Oct. 2018.

[2] Ali M. Eltamaly, and Nasr A. Elghaffar, Amer. (2017). Techno-Economical Study of Using Nuclear Power Plants for Supporting Electrical Grid in Arabian Gulf. Technol Econ Smart Grids Sustain Energy Journal. DOI 10.1007/s40866-017-0031-8 
[3] Ali Eltamaly, Amer Nasr A. Elghaffar, Yehia Sayed and Abu-Hashema M. El-Sayed. (2018). Advanced Control Techniques for Enhance the Power System Stability. Insite Energy Science Journal, PiscoMed Publishing Pte. Ltd. Singapore.

[4] Ali Eltamaly, Yehia Sayed, Abou-Hashema El-Sayed and Amer Nasr A. Elghaffar. (2018). Multi-Control Module Static VAR Compensation Techniques for Enhancement of Power System Quality. Annals of Faculty Engineering Journal. ISSN: 2601-2332, Aug. 2018.

[5] Amer Nasr A. Elghaffar, Ali M. Eltamaly, Yehia Sayed and Abou-Hashema M. El-Sayed. (2018). Enhancement of Power System Quality Using Static Synchronous Compensation (STATCOM). IJMEC, EISSN: 2305-0543 Vol. 8(30), Oct. 2018, PP. 3966-3974.

[6] Ali M. Eltamaly and Amer Nasr A. Elghaffar. (2017). Load Flow Analysis by Gauss-Seidel Method; A Survey. International Journal of Mechatronics, Electrical and Computer Technology (IJMEC), PISSN: 2411-6173, EISSN: 2305-0543.

[7] Adel A. Elbaset, Yehia Sayed and Amer Nasr A. Elghaffar. (2017). Treatment Effect of EMF on The Protection IEDs in HV Substations. Nineteenth International Middle East Power Systems Conference (MEPCON). DOI: 10.1109/MEPCON.2017.8301245

[8] Emil Iggland, Roger Wiget and Spyridon Ch. (2015). Multi-Area DC-OPF for HVAC and HVDC Grids. IEEE Transactions on Power Systems (Volume: 30, Issue: 5), DOI: 10.1109/TPWRS.2014.2365724.

[9] Wanlu Li; Libao Shi; Liangzhong Yao; Yue Zhao; Zhou Jian; Yixin Ni. (2014). Comparison of HVAC and HVDC based grid integration on wind farm. 2014 International Conference on Power System Technology. DOI: 10.1109/POWERCON.2014.6993947.

[10] Yidong Hong and Tao Yu. (2013). Reliability Improvement Strategies for HVDC Transmission System” Energy and Power Engineering, Vol 5, 52-56.

[11] H. Nouri, A. T. (2015). Numerical Analyze of Corona Discharge on HVDC Transmission Lines" World Academy of Science, Engineering and Technology, International Journal of Electrical, Computer, Energetic, Electronic and Communication Engineering Vol:9, No:6,

[12] Project group WPS4-1050. (2010). Control of VSC-BASED HVDC transmission systems for OFFSHORE Wind power plants "Master Thesis, Department of Energy Tehnology Pontoppidanstr_de 101 Aalborg University, Denmark.

[13] Ali M. Eltamaly and Amer Nasr A. Elghaffar. (2017). Modeling of distance protection logic for out-ofstep condition in power system. Electrical Engineering Journal, DOI: 10.1007/s00202-017-0667-3.

[14] LiansongXiong, Fang Zhuo and Feng Wang (2016). Static Synchronous Generator Model: A New Perspective to Investigate Dynamic Characteristics and Stability Issues of Grid-Tied PWM Inverter. IEEE Transactions, V.31, Is.:9, PP: 6264 - 6280; ISSN: 0885-8993.

[15] Mujib J. Pathan and V. A Kulkarni. (2016). Fault annalysis of HVDC transmission systems. International Journal of Electrical Engineering \& Technology (IJEET) Volume 7, Issue 3, pp.106-116.

[16] Md Mizanur Rahman1, Md. Fazle Rabbi, Md. Khurshedul Islam and F. M. Mahafugur Rahman (2014). HVDC over HVAC Power Transmission System: Fault Current Analysis and Effect Comparison. Conference Paper.

[17] Tomasz Drobik. (2010). High-voltage direct current transmission lines. IEEE Conference Publishing ul. Pulaskiego 32/13, 46-100 Namyslow, Poland.

[18] H.R. Chamorro and G. Ramos. (2015). Harmonic and power flow hybrid controller applied to VSC based HVDC stations.

[19] Manohar Singh, B.K Panigrahi and R. P. Maheshwari. (2011). Transmission line fault detection and classification. International Conference on Emerging Trends in Electrical and Computer Technology (ICETECT), ISBN: 978-1-4244-7926-9, DOI: 10.1109/ICETECT.2011.5760084.

[20] Jorge Santam. (2011). Analysis of power systems under fault conditions. master of science, in electrical and electronic engineering at california state university, sacramento

[21] Anubha Gupta, Sunil V Chandran and S. S. Bhat. (2014). Simultaneous fault analysis. International Conference on Power, Automation and Communication (INPAC), India, DOI: 10.1109/INPAC.2014.6981131.

[22] Ruyuan Han and Qifeng Zhou. (2016). Data-driven solutions for power system fault analysis and novelty detection.11th International Conference on Computer Science \& Education (ICCSE), ISBN: 978-1-50902218-2, DOI: 10.1109/ICCSE.2016.7581560.

[23] Gil Marques and Matteo Iacchetti. (2016). Overcurrent estimation in a doubly-fed induction generator-DC system during a voltage dip in the dc grid" IET Renewable Power Generation, ISSN: 1752-1416, Page(s): $1024-1032$. 
[24] Ali M. Eltamaly and Amer Nasr A. Elghaffar. (2017). HVDC System Control between Different Frequencies Networks and Fault Analysis with HVAC System. IEETJ, Vol-1.

[25] Ali M. Eltamaly, Amer Nasr A. Elghaffar. (2017). A Survey: HVDC System Operation and Fault Analysis. Annals Engineering Jounal ISSN: - Vol.4.

[26] SmkoZangana and Ergun Ercelebi. (2016). Enhance Power Quality by HVDC System, Comparison Technique between HVDC and HVAC Transmission Systems "World Academy of Science, Engineering and Technology International Journal of Electrical, Computer, Energetic, Electronic and Communication Engineering Vol: 10, No: 2.

Citation: Ali M. Eltamaly, et.al. "HVDC over HVAC Transmission System: Fault Conditions Stability Study”, International Journal of Research Studies in Electrical and Electronics Engineering, 5(1), pp 24-37. DOI: http://dx.doi. org/10.20431/2454-9436.0501004

Copyright: () 2019 Authors. This is an open-access article distributed under the terms of the Creative Commons Attribution License, which permits unrestricted use, distribution, and reproduction in any medium, provided the original author and source are credited. 